\title{
The Role of Digital Marketing in Creating an Information System Conducive to Social Development
}

\author{
Marina Andriianova ${ }^{1},{ }^{*}$ Valeriia Kruchinina ${ }^{2}$ \\ ${ }^{1}$ Moscow State Institute of International Relations (MGIMO University), Russia \\ ${ }^{2}$ ISS - Intelligent Security Systems (ISS-Soft Ltd), Russia \\ "Email: m.andriyanova@odin.mgimo.ru
}

\begin{abstract}
Digital marketing tools and technologies are an integral part of all spheres of life in the modern world. In economically developed countries, digital technologies are a tool for influencing both manufacturers of goods and services and consumers. This article discusses the impact of digital marketing tools on production processes, the company's performance and public processes. One of the critical changes that digital marketing has brought is scaling up and strengthening information exchange between consumer and manufacturer and involving manufacturers in solving the most pressing social issues.
\end{abstract}

Keywords: Digital marketing, Marketing communication, Digitisation, Human development level.

\section{INTRODUCTION}

The basis of any economic system is the interaction between manufacturers and consumers of goods and services. In a modern economy, the process of transferring information about a product or service to a target audience is known as marketing communication. In a broad sense, marketing communications are the complex of all relationships formed by the company with the external environment. Marketing tools can be the product itself, its packaging and labelling; advertising and PR; trade and direct marketing; branding; online promotion; loyalty programs; sponsorship and philanthropy; personal sales and after-sales services; various kinds of events (exhibitions, seminars, conferences). As a result, the purpose of all marketing communications is to convince the consumer (potential or actual) that the product or service guarantees the fullest satisfaction of its needs, which should give an impulse to acquire the offered goods or services. The nature of the current producer-consumer relationship is embodied in marketing communications. Thus, the content and trends of marketing communications in general, the production system's role in public life can be gauged.

Digital marketing was initially viewed from a purely applied, instrumental point of view. It was considered a set of time-appropriate tools to enable the producer to maintain effective communication with consumers through modern technological capabilities. There was some concern for society that the continuous technological development and the development of increasingly sophisticated digital marketing technologies can give manufacturers of goods and services the tools to manipulate consumers, so these tools directly threaten individual liberty. In practice, however, it emerged that a narrow toolkit approach to assessing the role of digital marketing technologies does not fully reflect their potential to influence public life. It turns out that digital marketing is making significant changes to the coordinate system defining the modes and modalities of interaction between manufacturers and consumers, and it could also create conditions for changing the balance of power between them.

The purpose of this research is to identify and study the changes that digital marketing makes to the coordinate system determining the ways and manner of interaction between producers and consumers and the distribution of forces between them. The most effective methods for achieving this goal should be recognised research methods that allow diagnostics based on weak signals, i.e. based on emerging, emerging problems. In this case, we discuss the qualitative and quantitative 
(content analysis) analysis of information, interpretation, and systematisation. The following sources were selected as the primary sources of information for this study: 1) digital advertising; 2) publications in Internet sources (manufacturer news, consumer reviews, discussions on forums, social networks, etc.). The analysis of such information makes it possible to form a holistic and relevant idea of the most relevant changes like interaction and the relationship between producers of goods and services and their consumers.

\section{RESEARCH}

Marketing communications is a relatively wellresearched area of marketing activity. However, the dynamics of the development of forms and content of marketing communications continuously keep them focused on scientists and practitioners' attention.

Thus, N. Capon, R. Capon, J. Hulbert emphasised that a modern company's manager needs to learn from best and worst marketing practices because that is an application area and the experience in this area is crucial. They emphasise that the ability to build effective communications in modern business is a critical element in the fight for the market. J. Kagan has convincingly proved in his research that digital marketing is now mainstream, so it is a connecting element that brings together all elements of marketing activities to establish effective communication with the client. The unique role of digital marketing in general and its technologies and tools was studied in the works of a large group of specialists, including, for example, K. Jerath, M. Brown, A. Aribag, T. Otter, D. Zantedeschi, G. Allenby, T. Bentley, D. Curry, M. Dotson, T. Henderson, E. Honka, R. Kohli, K. Jedidi, S. Seiler, X. S. Wang, M. V. Andriianova.

Moreover, the research on modern marketing practices indicates the emergence of another significant trend in modern marketing practices - the increasing importance of the customer's response to the product's value and attributes (or service) due to all aspects of its implementation. Similar conclusions can be found in the works by K. Jerath, P. Fader, B. G. S. Hardie, M. Braun, D.A. Schweidel, E.M. Stein, D. Lerman, R. J. Morais, D. Luna, C.W. Chang, J.Z. Zhang, K. Wilcox, J. Laran, S. Sen.

Agreeing with the findings and results of colleagues' research and relying on them as a starting point, in our research we intend to focus on studying the current changes in the process of marketing communications and their role in the life of modern society.

The most useful research methods of occurred changes are those that make it possible to diagnose weak signals, i.e. signs of emerging challenges or problems. We considered the following sources of information for this research: 1) digital advertising; 2) publications in web-based resources (news on the producer's website, consumer feedback, discussions in forums, social networks, etc.) [1].

The analysis of the information provided on these services allowed for creating a coherent and relevant understanding of the most relevant changes in interaction and the relationship between manufacturers and consumers of the produced goods.

In a generic form, the sequence of the marketing communication process is presented in figure 1 .

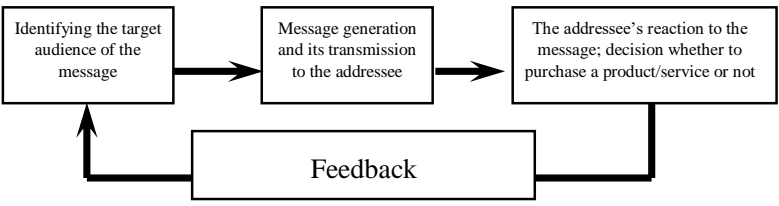

Figure 1 The sequence of the marketing communication process.

The pivot point of any marketing activity is identifying the target audience and its needs that can be satisfied with a specific product or service. Based on the characteristics of the target audience, a particular information pattern is formed.

The pattern is a set of rational and emotional signals that must convince a potential customer that it is the product with an optimum set of consumer characteristics from the customer needs, optimum price and quality ratio. If this can be done, the consumer decides to acquire the product or service. The consumer may provide feedback on the process of selecting, acquiring goods, or express their emotions [2].

The structure of marketing communication has not changed in the digital age, but the content of each stage of the marketing communication process has changed significantly.

Internet search engines are a projection of modern thinking. By tracking the structure and content of requests, it is possible to identify current customer needs and opportunities as a buyer accurately. Modern business has a wide range of tools to achieve this goal, for example:

- Facebook, Instagram and other social media advertising offices which track user actions, including browsing and site history;

- Pixel Facebook is an analytics tool that allows to examine the actions of people on the website and transmit generated data to Events Manager;

- KISSmetrics is an analytics tool that allows creating a link «email user - his actions», by which the business gets full information about those users who left their data;

- Comizer is a specialised tool for the audience geotargeting. 
Accurate identification of target audience and full understanding of its needs make it possible to target the advertising content with such digital-marketing tools such as:

- Origami context advertising management platform;

- Elama service, which allows running advertising campaigns simultaneously in several advertising systems;

- Google Adwords context advertising implementation tool.

To express buyer's reactions and provide feedback in the modern digital world, the following resources can be used:

- social media pages;

- social media groups in which the buyer is a member;

Table 1. Top 20 countries by human development level [5]

\begin{tabular}{|c|c|c|c|c|c|c|c|}
\hline 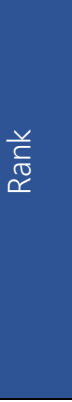 & $\begin{array}{l}\frac{\lambda}{f} \\
\frac{5}{5} \\
0\end{array}$ & 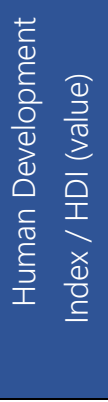 & 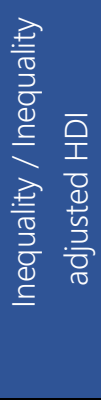 & 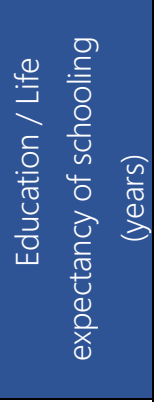 & 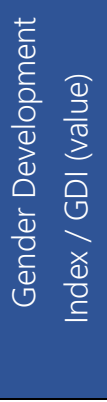 & 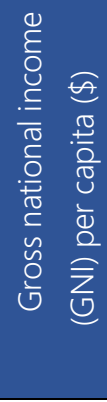 & 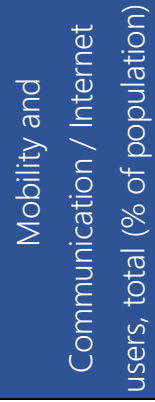 \\
\hline 1 & Norway & 0.954 & 0.889 & 18.1 & 0.990 & 68059 & 96.5 \\
\hline 2 & Switzerland & 0.946 & 0.881 & 16.2 & 0.963 & 59375 & 89.7 \\
\hline 3 & Ireland & 0.942 & 0.872 & 18.8 & 0.975 & 55660 & 84.5 \\
\hline 4 & Germany & 0.939 & 0.861 & 17.1 & 0.968 & 46946 & 89.7 \\
\hline 5 & Hong Kong & 0.939 & n.a. & 16.5 & n.a. & 60221 & n.a. \\
\hline 6 & Australia & 0.398 & 0.862 & 22.1 & 0.975 & 44097 & 86.5 \\
\hline 7 & Iceland & 0.938 & 0.885 & 19.2 & 0.966 & 47566 & 99.0 \\
\hline 8 & Sweden & 0.937 & 0.874 & 18.8 & 0.982 & 47955 & 92.1 \\
\hline 9 & Singapore & 0.935 & 0.810 & 16.3 & 0.988 & 83793 & 88.2 \\
\hline 10 & Netherlands & 0.933 & 0.870 & 18.0 & 0.967 & 50013 & 94.7 \\
\hline 11 & Denmark & 0.930 & 0.873 & 19.1 & 0.980 & 48836 & 97.6 \\
\hline 12 & Finland & 0.925 & 0.876 & 19.3 & 0.990 & 41779 & 88.9 \\
\hline 13 & Canada & 0.922 & 0.841 & 16.1 & 0.989 & 43602 & 91.0 \\
\hline 14 & New Zealand & 0.921 & 0.836 & 18.8 & 0.963 & 35108 & 90.8 \\
\hline 15 & United Kingdom & 0.920 & 0.845 & 17.4 & 0.967 & 39507 & 94.9 \\
\hline 16 & United States & 0.920 & 0.797 & 16.3 & 0.991 & 56140 & 87.3 \\
\hline 17 & Belgium & 0.919 & 0.849 & 19.7 & 0.972 & 43821 & 88.7 \\
\hline 18 & Liechtenstein & 0.917 & n.a. & 14.7 & n.a. & 99732 & 98.1 \\
\hline 19 & Japan & 0.915 & 0.882 & 15.2 & 0.976 & 40799 & 84.6 \\
\hline 20 & Austria & 0.914 & 0.843 & 16.3 & 0.963 & 46231 & 87.7 \\
\hline
\end{tabular}

- manufacturer Youtube channel, pages in social networks;

- official manufacturer website;

- websites with reviews, such as trustpilot.com.

At first glance, modern digital marketing tools create more advantages and opportunities for manufacturers of goods and services. Indeed, manufacturers can collect a large amount of relevant data to understand their real and potential customers in depth. The manufacturers of goods and services can deliver advertising materials in a targeted manner, which significantly reduces the production and proliferation costs and increases its efficiency; manufacturers can easily and quickly receive feedback from customers, which allows them to keep their eyes on the ball. One might jump to the conclusion that the consumer would become a technical element in this system, a toy in the manufacturer's hands. But this is just the way it looks [3]. 
A more detailed analysis reveals that digital marketing contributes to a qualitative change in manufacturers and consumers' relationship [4]. This is particularly evident in the economically developed countries' markets, which have a high quality of life, human development, and digital marketing.

Quality of life and human development in economically developed countries are not determined only by income; other social rather than economic value factors are also important (table 1).

Modern consumers in developed countries are no longer only interested in consumer properties of goods and services. For decades now, consumers have begun to show a deep interest in how the goods and services they acquire are produced; the consumer community strained after monitoring workers' working, living, housing conditions, and access to health and education services. Companies that use child and slave labour were severely stigmatised. For this reason, it has become a common practice of using peculiar "weak signals" in developed economies. These signals demonstrate socially responsible manufacturers' behaviour to the public. For example, Lipton company places information on individual packages of tea bags about which type of social work it carries out on the plantations where the tea is grown.

What does the marketing communication process look like in such countries, in which digital marketing tools and technologies are used? High-quality targeting allows manufacturers to identify their target audience accurately; context advertising ensures targeted delivery of marketing information to stakeholders that value their rational and emotional values.

Mathematically accurate targeting sends an advertising message or information about the product or service to the person interested in this product. Therefore, the person will pay attention to the advertisement or information message. However, the consumer will evaluate goods not only from the point of view of its consumer qualities [6]. As a result, instead of an interest in a product or service, there may be questions or claims against the manufacturer. Digitisation has resulted in marketing materials being distributed online almost instantaneously, and they can be seen by users without any restrictions worldwide. If necessary, these materials cannot be removed from the public domain without a trace. Negative feedback from users can be expressed instantaneously; what is essential is that digitisation has created opportunities for coordinated consumer networking, lobby groups that force manufacturers to respond to current issues and challenges in public life and solve social challenges. To create organised groups with participants worldwide, various digital tools can be used, from the most specific groups in the familiar social networks to the more functional like Discord, Telegram, Change.org, etc.
So, it is the consumers' reaction in social media to the list of physical requirements for children, participating in the casting for Christmas angels' role, forced Mondelēz International, Milka chocolate manufacturer not only apologising but also getting out of the sponsorship of this list. Avon was obliged to apologise for promoting the anti-cellular line that consumers considered imposing specific Avon beauty standards. Brand Always agreed without objection to the transgender community's request to remove the Venus mirror's sign from the packaging of their products, because not all using Always products identify themselves as women. This may have been facilitated by the example of Victoria's Secret, a brand which under pressure from the public, was forced to embrace diversity and launch a plus-size collection, invite plus-size and transgender models to take part in Victoria's Secret show.

These processes, although still considered chaotic, are quite obvious. The manufacturers cannot fail to see and understand them [7]. For example, Fazer was very confused by one Internet user's question for what reason one of the chocolate varieties is called Geisha; Valio demonstrated a similar reaction in response to a question about why is there a man in a fez on the Greek yoghurt package. The reaction of manufacturers to the social burning issues gives impulse to the cancel culture phenomenon. Joanne Rowling has also grappled with this phenomenon. Paradoxically, society does not reject what she created; her writings and books, movies, and plays remain valuable. However, J. Rowling herself seems to have disappeared from the information space created around her works.

\section{RESULTS}

In economically developed countries, the market is saturated with the supply of goods and services, and the high level of income enables consumers to achieve their desired lifestyle. Because of this, the concept of the total product has begun to change. The importance of a worldview and ideological value of a product or service has increased. Manufacturers no longer have the right and opportunity to remain out of public life [8]. This is an objective process; digital marketing has become both an accelerator and an acid test of this process. Initially, digital marketing tools and technologies were conceived and later developed to improve the efficiency of enterprises' marketing activities, so it was a purely applied project with a strong commercial focus. So, there was no question that digital marketing tools and technologies would at least have the potential to play an essential role in social processes. However, it turned out that contemporary digital marketing is a frame of reference between manufacturers and consumers; digital marketing changes both the process, the nature, and the content of this relationship [9]. Digital marketing did not cause social changes, but it became a technical tool 
through which information exchange between manufacturers and consumers has become more extensive and more in-depth. It has also become another way of influencing manufacturers to solve public problems, but in a qualitatively different form, because producers could not withdraw or keep silent [10]. Nevertheless, it should be understood that not in any economic system digital marketing tools and technologies cause a similar effect; this requires certain conditions, namely a high standard of living, high levels of human development, and digital marketing (figure 2).

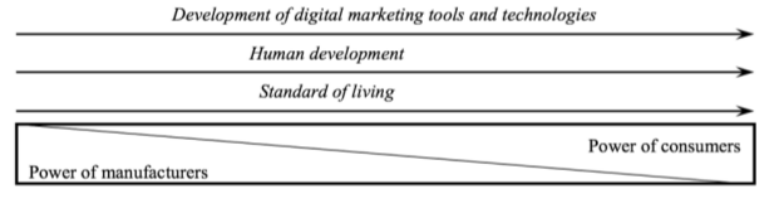

Figure 2 The ratio of the power of manufacturers and the power of consumers in the economically developed countries in the context of digital marketing communication.

The manufacturer's social responsibility is no longer enough for modern consumers; modern consumers demand that manufacturers become full participants in modern social processes and do not distance the production system from current challenges and public life issues. The production system may be an exclamation in public, which gains the right to be apolitical and remain neutral concerning processing issues of social and public life, only if it is a question of the survival of a particular social group (people, nation, etc.). The manufacturers of goods and services are already aware of these new trends and are trying to clarify the new rules of the market game [11]. The new relationship is currently in its initial development stage, so in some cases, manufacturers' actions appear excessive or illogical. Still, in one way or another, they demonstrate a desire to meet the demands of society.

For example, in early December 2020, the Nasdaq exchange, that deals with the securities of innovative companies, has taken the initiative that the shares of enterprises with at least one woman and at least one minority representative (LGBT community, national minority, etc.) in top management can be listed on the exchange. Companies that do not meet this requirement should give a public explanation for this inconsistency.

\section{CONCLUSIONS}

Nowadays, the digitisation of all spheres of public life is an objective fact. Probably, the speed and depth of the digitisation processes would only increase in the future. The nature and extent of changes in society resulting from digital change are challenging to access because in general digital change is a relatively new phenomenon in public life. However, digitisation's effects and consequences are considered exciting and relevant subjects for research regarding their importance to public life in general.

Active application of digital marketing tools and technologies in economically developed countries has become a factor contributing to the acceleration of qualitative changes in society. Digital marketing tools have created a new system of information exchange, which, on the one hand, enables consumers to obtain more valuable information about manufacturers of goods and services. On the other hand, provides rapid feedback that brings to the attention of manufacturers the demands of small and large social groups to which an appropriate response is required. Assessing these requirements and requests is a complex and controversial issue; however, the very fact that manufacturers have been involved as actively as possible in public life and the solution of current social burning issues.

\section{REFERENCES}

[1] N. Capon, R. Capon, J. Hulbert, Managing Marketing in the 21st Century, Wessex Inc., 2009, p. 691.

[2] J. Kagan, Digital Marketing: Strategy \& Tactics, Wessex Press Inc., 2018.

[3] K. Jerath, M. Brown, How the marketing technology landscape will transform in the new year. Retrieved from Adweek, 2019. Retrieved from: adweek.com

[4] A. Aribag, T. Otter, D. Zantedeschi, G. Allenby, T. Bentley, D. Curry, M. Dotson, T. Henderson, E. Honka, R. Kohli, K. Jedidi, S. Seiler, X.S. Wang, Advancing non-compensatory choice models in marketing, Customer Needs and Solutions 5 (2018) 82-92.

[5] Human Development Report Office, 2019 Retrieved from: hdr.undp.org

[6] M.V. Andriianova, Challenges in building effective marketing communications in a digital economy, Innovations and Investment 11 (2019) 103-107.

[7] K. Jerath, P. Fader, B.G.S. Hardie, European Journal of Operational Research, Marketing models for the customer-centric firm, European Journal of Operational Research 1 (2016) 340-350.

[8] M. Braun, D.A. Schweidel, and E.M. Stein, Transaction attributes and customer valuation, Journal of Marketing Research 52 (2015) 848-864.

[9] D. Lerman, R.J. Morais, D. Luna, The Language of Branding: Theory, Strategies, and Tactics, Routledge, 2017, p. 170.

[10] Chang, C.W., and J.Z. Zhang, The effects of channel experiences and direct marketing on customer 
retention in multichannel settings, Journal of Interactive Marketing 36 (2016) 77-90.

[11] K. Wilcox, J. Laran, S. Sen, Does Imitation Benefit the Imitated Brand? The Effects of Target Ambiguity and Processing Mindset on Judgment, Columbia Business School, 2018. 